TITLE PAGE

\title{
Acute hypotensive response to continuous and accumulated isocaloric aerobic bouts
}

Running head: Postexercise hypotension and aerobic exercise

Felipe A. Cunha ${ }^{1,2}$, Adrian W. Midgley ${ }^{3}$, Linda Pescatello ${ }^{4}$, Pedro P. Soares ${ }^{5}$ and Paulo Farinatti ${ }^{1,6}$

${ }^{1}$ Laboratory of Physical Activity and Health Promotion, University of Rio de Janeiro State, Rio de Janeiro, Brazil (e-mails: felipeac@globo.com; pfarinatti@gmail.com)

${ }^{2}$ Rehabilitation Sciences Graduate Program, Augusto Motta University Center (UNISUAM), Rio de Janeiro, Brazil (e-mail: felipeac@globo.com)

${ }^{3}$ Department of Sport and Physical Activity, Edge Hill University, Ormskirk, Lancashire, England (email: MidgleAd@edgehill.ac.uk)

${ }^{4}$ Department of Kinesiology, University of Connecticut, Storrs, United States (e-mail: linda.pescatello@uconn.edu)

${ }^{5}$ Department of Physiology and Pharmacology, Fluminense Federal University, Niterói, Rio de Janeiro, Brazil (e-mail: ppsoares@vm.uff.br)

${ }^{6}$ Physical Activity Sciences Graduate Program, Salgado de Oliveira University, Niterói, Rio de Janeiro, Brazil (e-mail: pfarinatti@gmail.com)

Address for correspondence: Prof. Dr. Paulo Farinatti. Institute of Physical Education and Sports, Laboratory of Physical Activity and Health Promotion, University of Rio de Janeiro State. Rua São Francisco Xavier 524 / sala 8121F - Maracanã, Rio de Janeiro, RJ, Brazil. CEP: 20550-013; Phone: (21) 2334-0775. E-mail: paulo.farinatti@pq.cnpq.br. 


\section{Acknowledgements}

This study was partially supported by the Carlos Chagas Filho Foundation for the Research Support in Rio de Janeiro and by the Brazilian Council for the Research Development.

\section{Conflict of Interest}

The authors have no conflict of interest to declare. 


\begin{abstract}
Evidence indicates that chronic reductions in blood pressure (BP) due to aerobic exercise depend on the ability to induce postexercise hypotension (PEH) after each training bout. The purpose of this study was to investigate PEH after isocaloric bouts of continuous and accumulated running. Ten healthy prehypertensive men (aged $27.6 \pm 3.5 \mathrm{yrs}$ ) performed the following bouts of exercise: a) A continuous bout (CONT) expending a total of $400 \mathrm{kcal}$; and b) An accumulated bout split into two x $200 \mathrm{kcal}$ (INTER1 and INTER2) to total $400 \mathrm{kcal}$ at $75 \%$ of oxygen uptake reserve. BP, mean arterial pressure (MAP) and heart rate variability were monitored $10 \mathrm{~min}$ before and $60 \mathrm{~min}$ after control and all exercise conditions. The decrease in MAP over time after continuous (400 kcal) and accumulated (2 x $200 \mathrm{kcal})$ bouts of exercise was more pronounced than during control (mean diff between 1.6 and $5.4 \mathrm{mmHg}, P \leq$ 0.01 ), although the magnitude of change was similar between continuous and accumulated bouts (mean diff $=0.1 \mathrm{mmHg}, P=0.79)$. Concomitant to the $\mathrm{PEH}$, sympathovagal balance was inversely related to changes in MAP after isocaloric bouts performed continuously and cumulatively $(\mathrm{r}=-0.70$ and $-0.85, P=$ 0.002 and 0.019 , respectively). In conclusion, BP decreased to similar levels after continuous and accumulated acute aerobic exercise matched for total energy expenditure. Our findings also indicate that the recovery pattern of cardiac autonomic activity may have an important role in eliciting PEH.
\end{abstract}

Keywords: aerobic training, blood pressure, energy expenditure, heart rate variability, parasympathetic modulation, sympathetic modulation. 


\section{Introduction}

Regular physical exercise, especially aerobic exercise, is recommended for the prevention, treatment, and control of hypertension [32]. Accordingly, the American College of Sports Medicine (ACSM) recommends aerobic exercise for 30 to $60 \mathrm{~min}$ per day, equivalent to an energy expenditure of 150 to 400 kcal per day, performed continuously or cumulatively, on most days of the week, to lower blood pressure by 5 to $7 \mathrm{mmHg}$ among adults with hypertension [32]. There is evidence that the reduction in blood pressure due to exercise training may be moderated by accumulated acute bouts of exercise [23].

Multiple short bouts, rather than longer continuous bout of physical exertion, have been recommended as an approach to increasing the leisure time allocated to physical activity and enhancing exercise adherence among sedentary individuals, of which often have hypertension [9,32]. Nevertheless, data from previous studies that have investigated differences in the magnitude of postexercise hypotension (PEH) between continuous and accumulated exercise are controversial. Some studies, for example, suggested that accumulated acute exercise may elicit greater PEH than continuous acute exercise [2,3,22,30], while another indicated continuous and accumulated acute exercise bouts elicited similar blood pressure reductions [28]. However, none of those studies applied isocaloric exercise bouts and, therefore, the exercise volume performed may have been a potential confounding factor [10] explaining the inconsistencies in this literature. This is an important methodological issue, since the exercise pressor response, which seems to influence blood pressure after exercise, has been shown to be affected by the total amount of muscle work performed and is a surrogate of exercise volume [5,17]. A recent study by Cunha et al. [13], for example, investigated the effects of short-term maximal exercise performed with different exercise modes (cycling, walking, and running) on the magnitude of PEH in healthy men, and observed that only running (exercise mode involving greater energy expenditure) was able to induce PEH. Within a practical context, whether or not PEH occurs might be a result of total energy expenditure [13]. Consequently, continuous and accumulated aerobic exercise can only be compared if the total work performed in each type of exercise has been equated. Another important question is whether the magnitude of $\mathrm{PEH}$ depends on the resting blood pressure status of the individual, regardless of whether 
the exercise was performed continuously or cumulatively, since the baseline blood pressure status seems to be a more important moderator of PEH [33,34].

Heart rate variability (HRV) has emerged as a noninvasive physiological marker for evaluating modulation of cardiac autonomic nervous system activity, describing shifts in autonomic balance [15], and being widely used to describe autonomic variation concomitant to PEH. Notably, sympathetic activation and autonomic balance seem to influence the recovery pattern of blood pressure after exercise $[13,30,36,38]$. Although the precise mechanisms involved in PEH remain unknown, it is well accepted that blood pressure is determined by the relationship between cardiac output $(\mathrm{Q})$ and systemic vascular resistance (SVR) and that PEH would be due to either central factors (i.e. decreased Q in response to lower muscle sympathetic nerve activity and consequent baroreflex resetting with decreased efferent cardiac sympathetic activity) or peripherals factors (i.e. reduction in SVR in response to sustained local vasodilation by the release of prostaglandins and histamine $\mathrm{H}_{1}$ and $\mathrm{H}_{2}$ receptors) [5,17]. Some indicators suggest that sympathetic neural activity and baroreflex resetting may be inhibited during PEH, which could cause a reduction in SVR [18]. However, evidence regarding the role of autonomic activity in PEH is controversial. Park et al. [30] found a decrease in sympathetic activity and an increase in parasympathetic activity concomitant to PEH after accumulated bouts of walking (e.g., 4 x 10-min performed once per hour), while others $[13,36,38]$ suggested a compensatory increase in sympathetic activity might occur to offset the PEH and the baroreflex resetting. A question therefore arises: to what extent does PEH accompany a shift in cardiac autonomic balance, as assessed by HRV?

The main aim of the present study was to compare PEH following accumulated and continuous isocaloric bouts of running in healthy prehypertensive men. A second aim was to investigate the extent to which the magnitude of PEH is correlated to baseline blood pressure status. Whether sympathetic and parasympathetic cardiovascular responses assessed by HRV after each acute exercise bout are related to PEH also was investigated. 


\section{Materials \& Methods}

\section{Participants}

Ten healthy prehypertensive men participated in the study. Inclusion criteria consisted of a mean screening systolic blood pressure (SBP) of 120-139 mmHg and/or diastolic blood pressure (DBP) of 80$89 \mathrm{mmHg}$. All participants were recreationally active (i.e. $20-60 \mathrm{~min} / \mathrm{session}, 2-5$ times/wk) for at least six months prior to the study. The exclusion criteria were: a) cardiovascular disease and diabetes; b) use of drugs that could affect the cardiovascular responses or any ergogenic substances; c) smoking; and d) bone, joint, or muscle problems that could limit the performance of exercise. The study was performed in accordance with the ethical standards required by the journal [19] and was approved by institutional ethics committee board (0222.0228.000-11). All participants provided written informed consent.

Blood pressure screening was performed by a single evaluator using a calibrated mercury column sphygmomanometer (Heidji, São Paulo, Brazil) and a stethoscope (Sprague Rappaport, Omron, USA) after participants remained seated for $10 \mathrm{~min}$, according to the recommendations of the American Heart Association [31]. Participants were instructed to remain relaxed and to avoid talking during the measurements. The cuff was placed on the right arm, so that the inferior extremity remained at a level within $2.5 \mathrm{~cm}$ of the antecubital fossa. The arm was supported at heart level, and the bladder of the cuff encircled $80 \%$ of the arm circumference. The mercury column was deflated at $2-3 \mathrm{mmHg} / \mathrm{s}$, until Korotkoff sounds were heard, which corresponded to systolic (first sound) and diastolic (fifth sound) values. The readings were registered to the nearest $2 \mathrm{mmHg}$. Blood pressure was calculated as the mean of three readings taken on the same day with 5-min intervals between measurements.

\section{Experimental design}

A schematic of the study design is shown in Figure 1. In total, each participant visited the laboratory on four separate days. On the first visit, participants were screened for hypertension followed by anthropometric measurements. Resting blood pressure and HRV were then measured at rest for 60 min 
('control' condition). Thereafter, subjects were familiarized with the equipment and test protocols to be used in subsequent visits.

On the second visit, a cardiopulmonary exercise test (CPET) was performed for determining maximal oxygen uptake $\left(\mathrm{VO}_{2 \max }\right)$. The third and fourth visits were separated by $48-72 \mathrm{hr}$ and consisted of performing isocaloric exercise bouts at $75 \%$ of oxygen uptake reserve $\left(\mathrm{VO}_{2} \mathrm{R}\right)$. During one of the visits the exercise bout was continuous and expended a total of $400 \mathrm{kcal}$. During the other visit the exercise bout was intermittent and consisted of $2 \times 200 \mathrm{kcal}$ sessions, separated by $1 \mathrm{hr}$ of passive rest, during which blood pressure and HRV were assessed. Allocation of test order for continuous and intermittent exercise bouts was randomized and counter-balanced across participants.

Before the exercise and control conditions, baseline assessments were performed during $10 \mathrm{~min}$ of bed rest in a quiet darkened room with the final 5 min used for data collection. Within $5 \mathrm{sec}$ of completing the exercise (or control session), participants were placed in a supine position, and data collection began 5 min after exercise (or control session) for a period of $60 \mathrm{~min}$ in a quiet room kept at a relatively constant temperature and relative humidity (ranged from 21 to $23^{\circ} \mathrm{C}$ and 50 to $70 \%$, respectively).

All exercise was performed on a motorized treadmill (Inbramed ${ }^{\mathrm{TM}}$ Super ATL, Porto Alegre, RS, Brazil). All laboratory visits were approximately the same time of day (between 07:00 and 11:00 a.m.).

\section{INSERT FIGURE 1}

\section{Blood pressure assessment}

Resting blood pressure was assessed by an oscillometric device (Spacelabs Medical ${ }^{\mathrm{TM}}$ model 90207 ; Spacelabs Inc., Redmond, WA, USA). The blood pressure monitoring followed standard procedures [35] and the criteria of the British Hypertension Society [29], including a calibration check before each experiment according to the manufacturer's instructions. Blood pressure recordings after exercise bouts and the non-exercise control session were obtained during $60 \mathrm{~min}$ at $20 \mathrm{~min}$ intervals in a quiet room and in a supine position. The control session mimicked the exercise bouts in that subjects remained seated at 
rest for $20 \mathrm{~min}$ and blood pressure was assessed by the same protocol as used before and after the exercise bouts in a supine position.

\section{Heart rate variability assessment}

The HR and HRV were recorded concomitantly to the blood pressure assessment, by a telemetric HR monitor (RS800cx, Polar ${ }^{\mathrm{TM}}$, Kempele, Finland). The R-R intervals were downloaded by Polar Precision Performance Software (Polar ${ }^{\mathrm{TM}}$, Kempele, Finland) and averaged for each $30 \mathrm{sec}$ window using a sampling frequency of $1000 \mathrm{~Hz}$. Before analysis, all R-R intervals were visually inspected for artifacts in order to make interpolation corrections on the sequences [37]. This was necessary in less than $1 \%$ of the sequences in each subject. A Fast Fourier Transform (Welch's method) with a Hanning window and 50\% overlap was used to estimate the power density spectrum of R-R interval variability using a customized routine (Mathworks ${ }^{\mathrm{TM}}$, Natick, MA, USA). The beat-by-beat R-R interval series were then converted into equally spaced time series with $200 \mathrm{~ms}$ intervals using cubic spline interpolation [37].

The ratio between low frequency and high frequency bands (LF:HF) was used as an index of sympathovagal balance, with the LF band $(0.04-0.15 \mathrm{~Hz})$ being considered as a marker of sympathetic predominance, and the HF band $(0.15-0.50 \mathrm{~Hz})$ as a marker of parasympathetic predominance [8]. The spectral values were expressed as normalized units (n.u.). To meet the stability requirement for performing spectral analysis, the first 5 min interval after each exercise bout was omitted from all HRV analyses. The control session and the HRV analyses following exercise were then used to calculate HRV indices according to previously established guidelines [37].

\section{Resting $\mathrm{VO}_{2}$ assessment}

Resting $\mathrm{VO}_{2}$ was determined prior to calculation of $\% \mathrm{VO}_{2} \mathrm{R}$ using well-controlled procedures recommended by Compher et al. [7]: abstention of physical exercise, alcohol, soft drinks and caffeine in the $24 \mathrm{~h}$ preceding the assessment, and fasting at least $8 \mathrm{~h}$ prior to the assessment. In the laboratory, subjects remained awake in a quiet environment for $10 \mathrm{~min}$, after which the $\mathrm{VO}_{2}$ was measured for 40 min in the supine position. The $\mathrm{VO}_{2 \text { rest }}$ was recorded as the average of the last 5 min of steady-state data 
assessed during 35 to $40 \mathrm{~min}$ (within-subject coefficient of variation $\leq 10 \%$ ) [11]. The $\mathrm{VO}_{\text {2rest }}$ was always measured at the same time of the day between 07:00 and 11:00 a.m.

\section{Maximal and submaximal exercise tests}

The $\mathrm{VO}_{2 \max }$ was determined using a ramp-incremented CPET protocol as described elsewhere [12]. Initially a non-exercise model, developed to estimate $\mathrm{VO}_{2 \max }$ in a healthy population aged 19 to 80 years was applied [26]. Based upon the predicted $\mathrm{VO}_{2 \max }$, the final work rate was calculated using the ACSM equation for running [1]. The mean \pm SD predicted final speed was $13.9 \pm 0.8 \mathrm{~km} \cdot \mathrm{h}^{-1}$ and workloads corresponding to $40 \%$ and $60 \%$ of predicted $\mathrm{VO}_{2 \max }$ were then calculated, respectively, for the 3-min warm-up [mean \pm SD: $5.6 \pm 0.3 \mathrm{~km} \cdot \mathrm{h}^{-1}$ ] and initial test workload [mean \pm SD: $8.3 \pm 0.5 \mathrm{~km} \cdot \mathrm{h}^{-1}$ ]. The treadmill inclination was set at $1 \%$ throughout the test [21]. The test was considered to have elicited peak capacity when at least three of the following criteria were observed [20]: a) maximum voluntary exhaustion defined by attaining a 10 on the Borg CR-10 scale; b) $\geq 90 \%$ predicted $\mathrm{HR}_{\max }[220$ - age] or presence of a heart rate (HR) plateau ( $\Delta \mathrm{HR}$ between two consecutive work rates $\leq 4$ beats $\left.\cdot \mathrm{min}^{-1}\right)$; $\mathrm{c}$ ) presence of a $\mathrm{VO}_{2}$ plateau $\left(\Delta \mathrm{VO}_{2}\right.$ between two consecutive work rates $\left.<2.1 \mathrm{~mL} \cdot \mathrm{kg}^{-1} \cdot \mathrm{min}^{-1}\right)$; and d) respiratory exchange ratio $>1.10$.

Based upon the $\mathrm{VO}_{2 \max }$ achieved during the CPET and the $\mathrm{VO}_{2 \text { rest }}$, values corresponding to $75 \% \mathrm{VO}_{2} \mathrm{R}$ were calculated to determine the intensity of the two isocaloric exercise bouts [mean \pm SD speed sessions: $\left.10.6 \pm 1.7 \mathrm{~km} \cdot \mathrm{h}^{-1}\right]$, as recommended elsewhere [10]. Each exercise bout was preceded by a 5 -min warmup at $5.5 \mathrm{~km} \cdot \mathrm{h}^{-1}$ and $1 \%$ grade. Expired gases were collected during exercise bouts via the metabolic cart. The exercise bouts were terminated when each participant had achieved a total energy expenditure of 400 or $200 \mathrm{kcal}$ in continuous or accumulated bouts of acute exercise, respectively.

Expired gases were collected using a VO2000 metabolic cart (Medical Graphics ${ }^{\mathrm{TM}}$, Saint Louis, MO, USA) and a silicone face mask (Hans Rudolph ${ }^{\mathrm{TM}}$, Kansas, MO, USA). Prior to testing, gas analyzers were calibrated according to the manufacturer's instructions using a certified standard mixture of oxygen (17.01\%) and carbon dioxide (5.00\%), balanced with nitrogen ( $\mathrm{AGA}^{\mathrm{TM}}$, Rio de Janeiro, RJ, Brazil). 
Flows and volumes of the pneumotacograph were calibrated with a syringe graduated for $3 \mathrm{~L}$ capacity (Hans Rudolph ${ }^{\mathrm{TM}}$, Kansas, MO, USA).

\section{Statistical Analyzes}

All statistical analyses were performed using IBM SPSS Statistics 22 software (SPSS ${ }^{\mathrm{TM}}$ Inc., Chicago, IL, USA). Descriptive sample data are presented as mean \pm SD [14]. The effect of Condition [control, continuous exercise (CONT), first intermittent exercise bout (INTER1), and second intermittent exercise bout (INTER2)] and Time [baseline and 60 min postexercise period (time-averaged at 20, 40, and 60 min)] on blood pressure and HRV indices were analyzed using marginal models using the SPSS MIXED procedure. Marginal models were used, as unlike repeated measures ANOVA, they allow different covariance structures to be assumed. The best fitting covariance structure was identified as that which minimized the Hurvich and Tsai's criterion value. Where there was a statistically significant main effect for Condition or a significant Condition x Time interaction effect, post hoc pairwise comparisons with Sidak-adjusted $P$ values were obtained. A custom hypothesis test using the TEST subcommand was used to investigate whether there were any differences in blood pressure and HRV indices for the mean recovery responses to the two intermittent exercise bouts (i.e. average of bout 1 and bout 2) versus the continuous exercise bout. Pearson correlations were used to determine the relationships between changes in SBP and DBP versus changes in the LF:HF ratio for the 60 min following the exercise bouts. The LF:HF ratio data were log transformed to correct for non-normal, heteroscedastic residuals derived from the marginal model. Two-tailed statistical significance was accepted as $P<0.05$.

\section{Results}

\section{Subject Characteristics}

Table 1 shows the mean \pm SD values for age, anthropometrical variables, resting physiological variables, maximal physiological responses from the cardiopulmonary exercise test, and $\mathrm{HR}$, absolute $\mathrm{VO}_{2}$, and times to achieve 400 (or 200) kcal during continuous and intermittent isocaloric exercise bouts at $75 \%$ $\mathrm{VO}_{2} \mathrm{R}$. 
Blood Pressure Response

Figure 2 shows the average blood pressure responses at baseline and during the $60 \mathrm{~min}$ following $\mathrm{C}$ and each exercise bout. There were main effects for Condition for SBP $(\mathrm{F}=63.0, P<0.001)$ and DBP $(\mathrm{F}=$ 20.1, $P<0.001$ ), and mean arterial pressure (MAP) $(\mathrm{F}=42.7, P<0.001)$, with the greatest reductions observed after INTER2 compared to control, followed by CONT compared to control. Significant interaction effects for SBP $(\mathrm{F}=6.6, P<0.001)$, DBP $(\mathrm{F}=2.6, P=0.008)$, and $\mathrm{MAP}(\mathrm{F}=4.5, P<0.001)$, however, indicated that the size of the differences between conditions was not constant across time.

At baseline there were no significant differences in blood pressure between conditions, except a 3.6 $\mathrm{mmHg}(95 \% \mathrm{CI}=1.4$ to 5.8$)$ lower SBP in INTER2 compared to control. Postexercise, the largest reductions in blood pressure occurred during the first $20 \mathrm{~min}$, with significant differences of 5.0-9.3, 7.28.3, and 4.0-8.7 mmHg observed between control and the postexercise periods for SBP, DBP, and MAP, respectively. The only non-significant difference was the $3.5 \mathrm{mmHg}$ mean difference in DBP between control and INTER1 $(95 \% \mathrm{CI}=-0.2$ to $7.2, \mathrm{P}=0.07)$. Blood pressure also was significantly lower after INTER2 compared to INTER1 (SBP: mean diff $=4.3 \mathrm{mmHg}, 95 \% \mathrm{CI}=1.6$ to 7.1 ; DBP: mean diff $=4.8$ $\mathrm{mmHg}, 95 \% \mathrm{CI}=1.1$ to 8.5 ; $\mathrm{MAP}:$ mean diff $=4.7 \mathrm{mmHg}, 95 \% \mathrm{CI}=2.0$ to 7.3$)$ and after $\mathrm{CONT}$ compared to INTER1 (SBP: mean diff $=2.1 \mathrm{mmHg}, 95 \% \mathrm{CI}=0.3$ to 3.9 ; DBP: mean diff $=3.7 \mathrm{mmHg}$, $95 \% \mathrm{CI}=0.06$ to 7.4 ; MAP: mean diff $=3.2 \mathrm{mmHg}, 95 \% \mathrm{CI}=0.5$ to 5.9$)$. Despite blood pressure increasing over time during the postexercise period, significant differences were still observed between control and some of the exercise conditions at 40 and $60 \mathrm{~min}$ (see Figure 2).

Significant reductions in blood pressure also were observed after INTER2 compared to INTER1 at 40 $\min$ (SBP: mean difference $=3.8 \mathrm{mmHg}, 95 \% \mathrm{CI}=1.7$ to 5.8 ; DBP: mean difference $=4.1,95 \% \mathrm{CI}=0.4$ to 7.8; MAP: mean difference $=4.0 \mathrm{mmHg}, 95 \% \mathrm{CI}=1.3$ to 6.7 ) and $60 \mathrm{~min}$ (SBP: mean difference $=2.8$ $\mathrm{mmHg}, 95 \% \mathrm{CI}=1.2$ to 4.4 ; MAP: mean difference $=3.3 \mathrm{mmHg}, 95 \% \mathrm{CI}=0.6$ to 6.0 ), and between INTER1 and CONT at $40 \mathrm{~min}$ (SBP: mean difference $=2.0 \mathrm{mmHg}, 95 \% \mathrm{CI}=0.2$ to 3.8 ) and $60 \mathrm{~min}$ (SBP: mean difference $=1.6 \mathrm{mmHg}, 95 \% \mathrm{CI}=0.1$ to 3.2 ). 
Custom hypothesis tests showed that there were no significant differences between the average blood pressure responses across the two intermittent exercise bouts versus CONT for SBP $(\mathrm{t}=0.1, P=0.92)$, $\operatorname{DBP}(\mathrm{t}=0.7, P=0.48)$, or $\operatorname{MAP}(\mathrm{t}=0.3, P=0.79)$.

\section{INSERT FIGURE 2}

\section{Heart Rate Variability Response}

Figure 3 displays the average HRV responses at baseline and during the $60 \mathrm{~min}$ following the control session and each exercise bout. There were significant main effects for Condition for $\mathrm{HR}(\mathrm{F}=54.0, P<$ 0.001), $\mathrm{LF}(\mathrm{F}=88.9, P<0.001), \mathrm{HF}(\mathrm{F}=159.1, P<0.001)$, and the LF:HF ratio $(\mathrm{F}=184.6, P<0.001)$. Like blood pressure, the greatest changes in HRV indices were observed after INTER2 compared to control and then after CONT compared to control. Significant interaction effects for $\mathrm{HR}$ (F $=17.8, P<$ 0.001), LF (F = 12.8, $P<0.001), \mathrm{HF}(\mathrm{F}=19.1, P<0.001)$, and lnLF:HF $(\mathrm{F}=22.6, P<0.001)$, however, indicated that the size of the differences between conditions was not constant across time.

At baseline there were no significant differences in HRV indices between conditions. Significant differences were observed between control and every time point of the post-exercise period for each condition for all HRV indices, except the difference in HR between control and INTER1 at 60 min (mean diff $=2 \mathrm{bpm}, 95 \% \mathrm{CI}=-5$ to 10$)$. Like the blood pressure responses, the greatest differences in HRV indices between conditions were observed during the first 20 min of postexercise recovery (see Figure 3).

Custom hypothesis tests showed that there were no significant differences between the average HRV indices responses across the two intermittent exercise bouts versus CONT for HR $(\mathrm{t}=1.5, P=0.13)$, LF $(\mathrm{t}=0.2, P=0.81), \mathrm{HF}(\mathrm{t}=1.0, P=0.31)$, or $\operatorname{lnLF}: \mathrm{HF}(\mathrm{t}=0.8, P=0.41)$.

\section{INSERT FIGURE 3}


Relationships between Baseline MAP, Change in MAP, and Change in LF:HF ratio

Figure 4 shows the relationship between the baseline MAP and the change in MAP from pre-to-post exercise. Significant relationships were observed for CONT, INTER1, and INTER2. Figure 5 shows the relationship between the change in the LF:HF ratio and the change in MAP from pre-to-post exercise. Significant relationships were observed for CONT and INTER2, but not for INTER1.

\section{INSERT FIGURE 4}

\section{Discussion}

The present study adds to current knowledge by investigating whether isocaloric bouts of continuous and accumulated running exercise would influence PEH in healthy prehypertensive young men. The major findings were: 1) The magnitude of the blood pressure reductions after continuous and accumulated acute exercise bouts matched for total energy expenditure were not different; 2) Continuous and a second accumulated exercise bouts matched for total energy expenditure (i.e. $400 \mathrm{kcal}$ ) provided greater PEH than the first intermittent exercise bout (200 kcal); 3) The magnitude of PEH was significantly correlated to baseline blood pressure status, where men with the highest baseline MAP experienced the greatest reduction in MAP after all exercise conditions; and 4) Sympathetic (LF component of HRV) and parasympathetic (HF component of HRV) activities remained significantly increased and decreased during the 60 min exercise recovery, resulting in a sympathetic overload (expressed by the LF:HF ratio) that was inversely correlated with the magnitude of PEH.

Previous studies have reported that the PEH was greater after accumulated compared to continuous bouts, with a mean difference in SBP and DBP of 2 to 11 and 4 to $6 \mathrm{mmHg}$, respectively $[2,22,30]$. On the other hand, similar to our findings, Miyashita et al. [28] observed that accumulated (10 x 3 min with rest intervals of $3 \mathrm{~min}$ ) and continuous (30 min) treadmill walking at approximately $42 \% \mathrm{VO}_{2 \text { peak }}(\approx 260 \mathrm{kcal})$ elicited similar SBP and DBP reductions (SBP $114 \pm 2 / \mathrm{DBP}=$ and $68 \pm 2 \mathrm{mmHg}$ ) among 15 healthy, young, recreationally active men $\left(\mathrm{VO}_{2 \max }=53.6 \pm 2.1 \mathrm{~mL} \cdot \mathrm{kg}^{-1} \cdot \mathrm{min}^{-1}\right)$. It is worthy noticing that the studies reporting different blood pressure responses following continuous and accumulated acute aerobic 
bouts failed to match the exercise sessions for total volume. Jones et al. [22], for instance, measured the blood pressure response in eight physically active men with normal blood pressure after continuous (30 min) and accumulated (3 x 10 min interspersed with 10 min rest intervals) bouts of cycling at $70 \%$ $\mathrm{VO}_{2 \max }$. Those authors acknowledged that although the exercise bouts have been superficially matched for external work (same intensity and duration), the actual energy expenditure was not measured. This methodological limitation is common to other studies investigating the effects of continuous versus accumulated acute isocaloric exercise on PEH [2,3,28,30].

The present study tried to overcome this limitation by matching the exercise sessions for energy expenditure. In contrast to previous studies [2,3,22,30], we found the magnitude of PEH was similar after the continuous and second accumulated bouts of running (see Figure 2). Moreover, the present study provides novel information concerning the role of exercise volume vs. intensity for inducing PEH. For instance, exercise performed with equivalent intensity (i.e. $75 \% \mathrm{VO}_{2} \mathrm{R}$ ) but smaller energy expenditure (e.g. first intermittent bout of $200 \mathrm{kcal}$ ) provoked lower acute blood pressure reduction compared to exercise bouts with greater energy expenditure (e.g. continuous and/or second intermittent bouts matched for total energy expenditure of $400 \mathrm{kcal}$ ) (see Figure 2). Only a few studies have compared the effects of different exercise durations on PEH. Some of them suggested that longer aerobic bouts would increase both the magnitude and duration of PEH [25], whereas others showed no impact of exercise duration on either magnitude or duration of PEH in normotensive [24] and hypertensive subjects [16]. However, none of these studies matched the exercise bouts for energy expenditure and, therefore, exercise volume, which seems to be a major determinant of the acute blood pressure response. This fact can partially explain the conflicting results.

On the other hand, regardless of whether the acute exercise bout is continuous or accumulated, the present data also concur with previous studies that observed a significant strong correlation between baseline blood pressure status and the magnitude of PEH $[33,34]$. In fact, our data showed a significant correlation between baseline MAP and the extent to which exercise lowered MAP after the continuous exercise bout ( $\mathrm{r}=-0.64, P=0.048)$, the first intermittent exercise bout $(\mathrm{r}=-0.72, P=0.020)$, and second intermittent 
exercise bout $(\mathrm{r}=-0.76, P=0.011)$ (see Figure 4), which in turn are in agreement with the findings of previous studies claiming that PEH is more marked in people with higher blood pressure status.

In the present study, the HRV analysis indicated that during the recovery period following the running bouts, sympathetic activity (i.e. LF component) increased while the parasympathetic activity decreased (i.e. HF component), resulting in higher sympathovagal balance (i.e. InLF:HF ratio) concomitant to the reduction in blood pressure (see Figures 2 and 3). Moreover, the acute reductions in blood pressure following aerobic exercise were negatively correlated to changes in sympathovagal balance, meaning that the greater the magnitude of $\mathrm{PEH}$, the greater the increase in the relative sympathetic activity (see Figure 5). Our findings are in agreement with previous reports, $[13,36,38]$ indicating that reductions in blood pressure following exercise were the result of a shift in cardiac autonomic balance, characterized by increased sympathetic and reduced parasympathetic activity. It could be speculated that such increase in sympathetic activity would be a physiological response to offset the reduction in blood pressure and to compensate for the resetting of the baroreflex [17], since the operating point of the arterial baroreflex is at a low blood pressure threshold $[4,27]$. If this is indeed the case, we can speculate that the PEH would somehow rely on the ability of peripheral vasodilation mechanisms to compensate for this autonomic central reaction. Further research is certainly warranted to clarify this issue.

In conclusion, the blood pressure reductions following isocaloric bouts of continuous or accumulated acute aerobic exercise were of similar magnitude. Additionally, the exercise performed with equivalent intensity but higher volume (e.g. $400 \mathrm{kcal}$ ) promoted greater PEH than bouts with smaller exercise volume (200 kcal). On the other hand, the PEH is more marked in people with higher resting blood pressure, regardless of whether the exercise is a continuous bout or two shorter accumulated bouts. Furthermore, the magnitude of PEH and sympathovagal balance were strongly and inversely correlated during the post-exercise recovery period. This indicates that the recovery pattern of cardiac autonomic activity assessed by HRV may have an important role in offsetting the decline in blood pressure after exercise. 


\section{References}

1. ACSM. ACSM's guidelines for exercise testing and prescription. 9th ed: Baltimore: Lippincott Williams \& Wilkins 2011

2. Angadi SS, Weltman A, Watson-Winfield D, Weltman J, Frick K, Patrie J, Gaesser GA. Effect of fractionized vs continuous, single-session exercise on blood pressure in adults. J Hum Hypertens 2010; 24: 300-302

3. Bhammar DM, Angadi SS, Gaesser GA. Effects of fractionized and continuous exercise on 24-h ambulatory blood pressure. Med Sci Sports Exerc 2012; 44: 2270-2276

4. Chandler MP, Rodenbaugh DW, DiCarlo SE. Arterial baroreflex resetting mediates postexercise reductions in arterial pressure and heart rate. Am J Physiol 1998; 275: H1627-1634

5. Chen CY, Bonham AC. Postexercise hypotension: central mechanisms. Exerc Sport Sci Rev 2010; 38: 122-127

6. Chobanian AV, Bakris GL, Black HR, Cushman WC, Green LA, Izzo JL, Jr., Jones DW, Materson BJ, Oparil S, Wright JT, Jr., Roccella EJ. Seventh report of the Joint National Committee on Prevention, Detection, Evaluation, and Treatment of High Blood Pressure. Hypertension 2003; 42: 1206-1252

7. Compher C, Frankenfield D, Keim N, Roth-Yousey L. Best practice methods to apply to measurement of resting metabolic rate in adults: a systematic review. J Am Diet Assoc 2006; 106: 881-903

8. Cooley RL, Montano N, Cogliati C, van de Borne P, Richenbacher W, Oren R, Somers VK. Evidence for a central origin of the low-frequency oscillation in RR-interval variability. Circulation 1998; 98: 556-561

9. Coquart JB, Lemaire C, Dubart AE, Luttembacher DP, Douillard C, Garcin M. Intermittent versus continuous exercise: effects of perceptually lower exercise in obese women. Med Sci Sports Exerc 2008; 40: 1546-1553 
10. Cunha FA, Catalao RP, Midgley AW, Gurgel J, Porto F, Farinatti PT. Do the speeds defined by the American College of Sports Medicine metabolic equation for running produce target energy expenditures during isocaloric exercise bouts? Eur J Appl Physiol 2012; 112: 3019-3026

11. Cunha FA, Midgley AW, Monteiro W, Freire R, Lima T, Farinatti PT. How long does it take to achieve steady state for an accurate assessment of resting VO2 in healthy men? Eur J Appl Physiol 2013; 113: 1441-1447

12. Cunha FA, Midgley AW, Monteiro WD, Farinatti PT. Influence of cardiopulmonary exercise testing protocol and resting $\mathrm{VO}(2)$ assessment on $\% \mathrm{HR}(\max ), \% \mathrm{HRR}, \% \mathrm{VO}(2 \mathrm{max})$ and \%VO(2)R relationships. Int J Sports Med 2010; 31: 319-326

13. Cunha FA, Midgley AW, Soares PP, Farinatti PT. Postexercise hypotension after maximal shortterm incremental exercise depends on exercise modality. Appl Physiol Nutr Metab 2015; 40: $605-614$

14. Dewland T, Androne A, Lee F, Lampert R, Katz S. Effect of acetylcholinesterase inhibition with pyridostigmine on cardiac parasympathetic function in sedentary adults and trained athletes. Am J Physiol Heart Circ Physiol 2007; 293: H86 - H92

15. Force T. Heart rate variability: standards of measurement, physiological interpretation and clinical use. Task Force of the European Society of Cardiology and the North American Society of Pacing and Electrophysiology. Circulation 1996; 93: 1043-1065

16. Guidry MA, Blanchard BE, Thompson PD, Maresh CM, Seip RL, Taylor AL, Pescatello LS. The influence of short and long duration on the blood pressure response to an acute bout of dynamic exercise. Am Heart J 2006; 151: 1322 e1325-1312

17. Halliwill JR, Buck TM, Lacewell AN, Romero SA. Postexercise hypotension and sustained postexercise vasodilatation: what happens after we exercise? Exp Physiol 2013; 98: 7-18

18. Halliwill JR, Taylor JA, Eckberg DL. Impaired sympathetic vascular regulation in humans after acute dynamic exercise. J Physiol 1996; 495 ( Pt 1): 279-288

19. Harriss DJ, Atkinson G. Ethical Standards in Sport and Exercise Science Research: 2016 Update. Int J Sports Med 2015; 36: 1121-1124 
20. Howley ET, Bassett DR, Jr., Welch HG. Criteria for maximal oxygen uptake: review and commentary. Med Sci Sports Exerc 1995; 27: 1292-1301

21. Jones AM, Doust JH. A $1 \%$ treadmill grade most accurately reflects the energetic cost of outdoor running. J Sports Sci 1996; 14: 321-327

22. Jones H, Taylor CE, Lewis NC, George K, Atkinson G. Post-exercise blood pressure reduction is greater following intermittent than continuous exercise and is influenced less by diurnal variation. Chronobiol Int 2009; 26: 293-306

23. Liu S, Goodman J, Nolan R, Lacombe S, Thomas SG. Blood pressure responses to acute and chronic exercise are related in prehypertension. Med Sci Sports Exerc 2011; 44: 1644-1652

24. MacDonald JR, MacDougall JD, Hogben CD. The effects of exercise duration on post-exercise hypotension. J Hum Hypertens 2000; 14: 125-129

25. Mach C, Foster C, Brice G, Mikat RP, Porcari JP. Effect of exercise duration on postexercise hypotension. J Cardiopulm Rehabil 2005; 25: 366-369

26. Matthews CE, Heil DP, Freedson PS, Pastides H. Classification of cardiorespiratory fitness without exercise testing. Med Sci Sports Exerc 1999; 31: 486-493

27. Miki K, Yoshimoto M, Tanimizu M. Acute shifts of baroreflex control of renal sympathetic nerve activity induced by treadmill exercise in rats. J Physiol 2003; 548: 313-322

28. Miyashita M, Burns SF, Stensel DJ. Accumulating short bouts of brisk walking reduces postprandial plasma triacylglycerol concentrations and resting blood pressure in healthy young men. Am J Clin Nutr 2008; 88: 1225-1231

29. O'Brien E, Coats A, Owens P, Petrie J, Padfield PL, Littler WA, de Swiet M, Mee F. Use and interpretation of ambulatory blood pressure monitoring: recommendations of the British hypertension society. BMJ 2000; 320: 1128-1134

30. Park S, Rink LD, Wallace JP. Accumulation of physical activity leads to a greater blood pressure reduction than a single continuous session, in prehypertension. J Hypertens 2006; 24: 1761-1770

31. Perloff D, Grim C, Flack J, Frohlich ED, Hill M, McDonald M, Morgenstern BZ. Human blood pressure determination by sphygmomanometry. Circulation 1993; 88: 2460-2470 
32. Pescatello LS, Franklin BA, Fagard R, Farquhar WB, Kelley GA, Ray CA, American College of Sports M. American College of Sports Medicine position stand. Exercise and hypertension. Med Sci Sports Exerc 2004; 36: 533-553

33. Pescatello LS, Guidry MA, Blanchard BE, Kerr A, Taylor AL, Johnson AN, Maresh CM, Rodriguez N, Thompson PD. Exercise intensity alters postexercise hypotension. J Hypertens 2004; $22: 1881-1888$

34. Pescatello LS, Kulikowich JM. The aftereffects of dynamic exercise on ambulatory blood pressure. Med Sci Sports Exerc 2001; 33: 1855-1861

35. Pickering TG, Hall JE, Appel LJ, Falkner BE, Graves J, Hill MN, Jones DW, Kurtz T, Sheps SG, Roccella EJ. Recommendations for blood pressure measurement in humans and experimental animals: part 1: blood pressure measurement in humans: a statement for professionals from the Subcommittee of Professional and Public Education of the American Heart Association Council on High Blood Pressure Research. Circulation 2005; 111: 697-716

36. Piepoli M, Coats AJ, Adamopoulos S, Bernardi L, Feng YH, Conway J, Sleight P. Persistent peripheral vasodilation and sympathetic activity in hypotension after maximal exercise. $\mathbf{J}$ Appl Physiol (1985) 1993; 75: 1807-1814

37. Task. Heart rate variability: standards of measurement, physiological interpretation and clinical use. Task Force of the European Society of Cardiology and the North American Society of Pacing and Electrophysiology. Circulation 1996; 93: 1043-1065

38. Teixeira L, Ritti-Dias RM, Tinucci T, Mion Junior D, Forjaz CL. Post-concurrent exercise hemodynamics and cardiac autonomic modulation. Eur J Appl Physiol 2011; 111: 2069-2078 
Table 1. Baseline subjects' characteristics $(\mathrm{N}=10)$.

\begin{tabular}{|c|c|c|}
\hline Moment & Variable & Mean \pm SD \\
\hline \multirow[t]{5}{*}{ Anthropometric assessment } & Age (yr) & $27.6 \pm 3.5$ \\
\hline & Height $(\mathrm{cm})$ & $173.9 \pm 8.7$ \\
\hline & Body mass (kg) & $78.0 \pm 8.5$ \\
\hline & $\mathrm{BMI}\left(\mathrm{kg} \cdot \mathrm{m}^{-2}\right)$ & $25.7 \pm 0.9$ \\
\hline & Body fat $(\%)$ & $13.1 \pm 3.9$ \\
\hline \multirow[t]{7}{*}{ Resting assessment } & $\mathrm{SBP}(\mathrm{mmHg})^{\mathrm{a}}$ & $125.9 \pm 4.3$ \\
\hline & $\mathrm{DBP}(\mathrm{mmHg})^{\mathrm{a}}$ & $84.0 \pm 3.2$ \\
\hline & HR rest (beats $\cdot \min ^{-1}$ ) & $68.3 \pm 4.8$ \\
\hline & LF power (n.u.) & $42.0 \pm 9.5$ \\
\hline & HF power (n.u.) & $49.6 \pm 7.7$ \\
\hline & LF:HF ratio (n.u.) & $0.9 \pm 0.3$ \\
\hline & Resting $\mathrm{VO}_{2}\left(\mathrm{~L} \cdot \min ^{-1}\right)$ & $0.2 \pm 0.1$ \\
\hline \multirow[t]{2}{*}{ Maximal cardiopulmonary exercise test } & $\mathrm{VO}_{2 \max }\left(\mathrm{L} \cdot \mathrm{min}^{-1}\right)$ & $4.2 \pm 0.7$ \\
\hline & $\mathrm{HR}_{\max }$ (beats. $\min ^{-1}$ ) & $195.8 \pm 5.7$ \\
\hline \multirow[t]{3}{*}{ Continuous bout } & Heart rate (beats. $\min ^{-1}$ ) & $174 \pm 7$ \\
\hline & Oxygen uptake $\left(\mathrm{L} \cdot \mathrm{min}^{-1}\right)$ & $3.0 \pm 0.6$ \\
\hline & Time to achieved $400 \mathrm{kcal}(\mathrm{s})$ & $1953 \pm 362$ \\
\hline \multirow[t]{3}{*}{ Accumulated intermittent bouts } & Heart rate (beats min $^{-1}$ ) & $168 \pm 6$ \\
\hline & Oxygen uptake $\left(\mathrm{L} \cdot \mathrm{min}^{-1}\right)$ & $2.9 \pm 0.6$ \\
\hline & Time to achieved $400 \mathrm{kcal}(\mathrm{s})$ & $2288 \pm 554$ \\
\hline
\end{tabular}

${ }^{\mathrm{a}}=$ Average of three screening BPs; $\mathrm{BMI}=$ body mass index $; \mathrm{VO}_{2}=$ oxygen uptake; $\mathrm{HR}=$ heart rate; $\mathrm{SBP}$ = systolic blood pressure; $\mathrm{DBP}=$ diastolic blood pressure; HF = high frequency band; LF = low frequency band; LF:HF ratio = sympathovagal balance. 


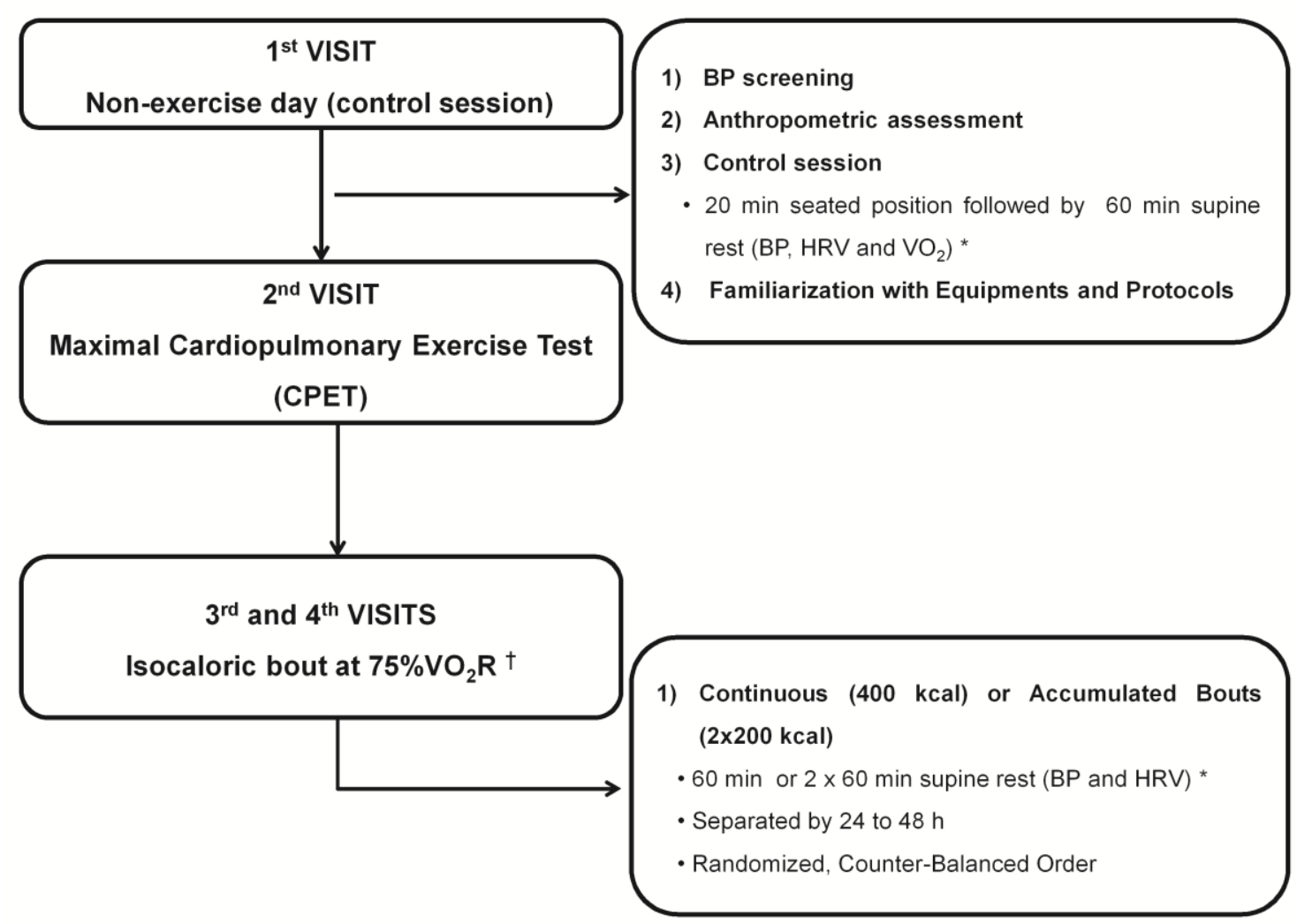

Figure 1. Study design overview. $\mathrm{VO}_{2} \mathrm{R}=$ oxygen uptake reserve; $\mathrm{BP}=$ blood pressure; $\mathrm{HRV}=$ heart rate variability; * Includes 10 min of baseline assessment in supine position; $\uparrow$ Includes 5 min warm-up and passive recovery. 

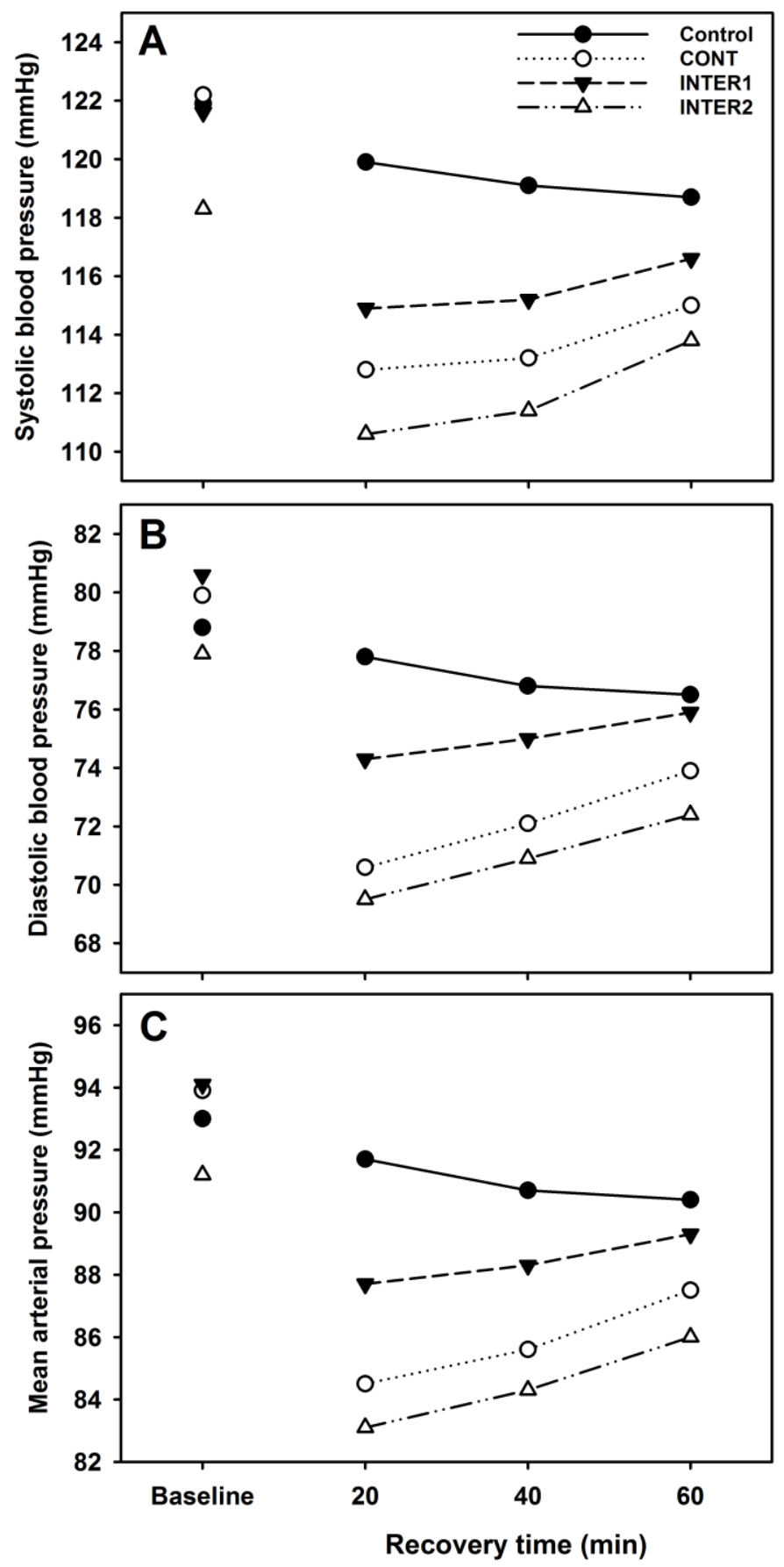

Figure 2. Mean systolic blood pressure $(\mathbf{A})$, diastolic blood pressure $(\mathbf{B})$, and mean arterial pressure $(\mathbf{C})$ at baseline and during the $60 \mathrm{~min}$ control and postexercise recovery periods. $*$ Significantly lower than Control. \# Significantly lower than first intermittent exercise bout (INTER1) $(P<0.05)$. Error bars have been omitted for clarity. 

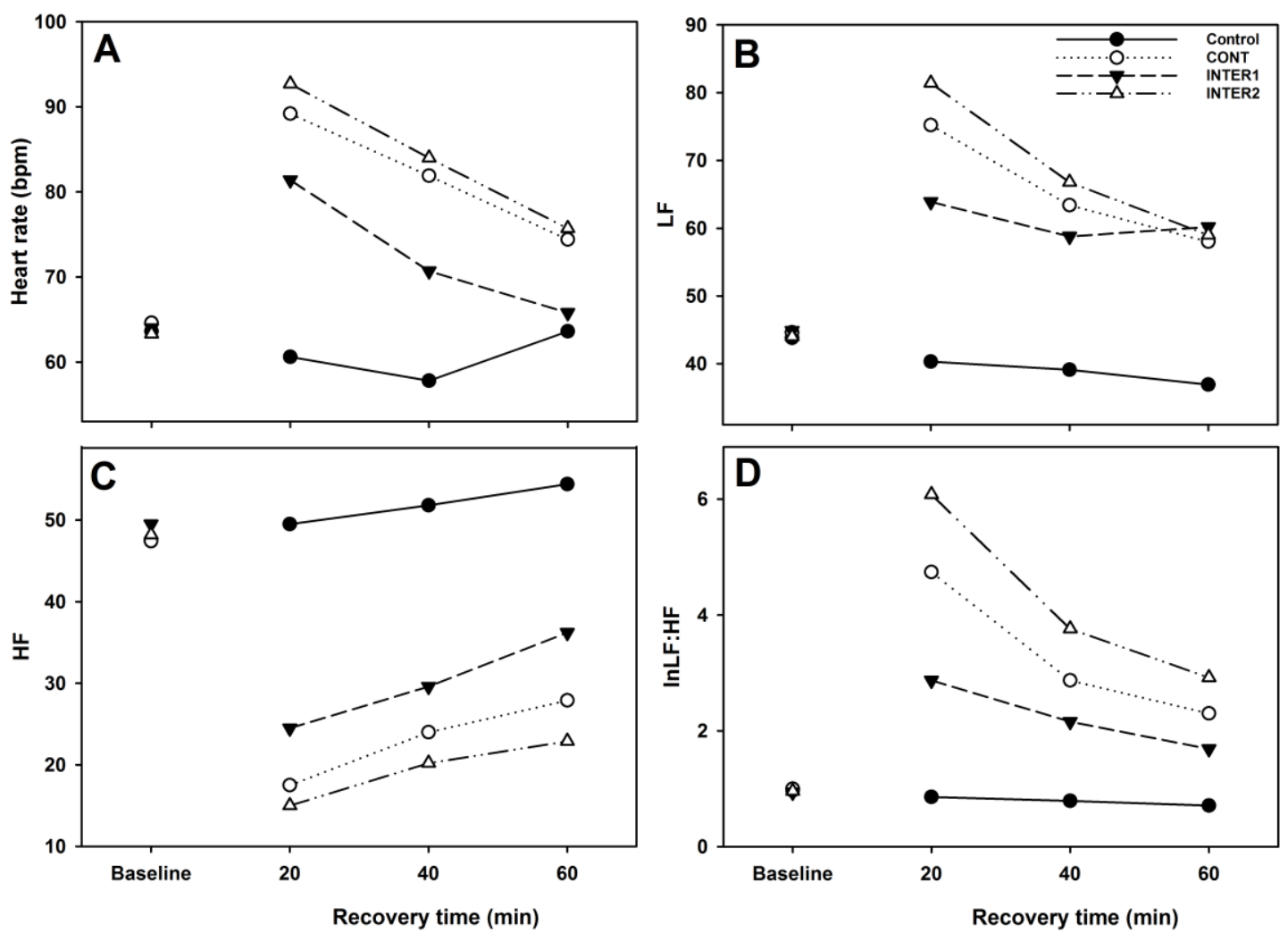

Figure 3. Mean heart rate (A), LF (B), HF (C), and logarithmically transformed LF:HF ratio (lnLF:HF) (D) at baseline and during the $60 \mathrm{~min}$ control and postexercise recovery periods. * Significantly lower than Control. \# Significantly lower than first intermittent exercise bout (INTER1) $(P<0.05)$. Error bars have been omitted for clarity. 


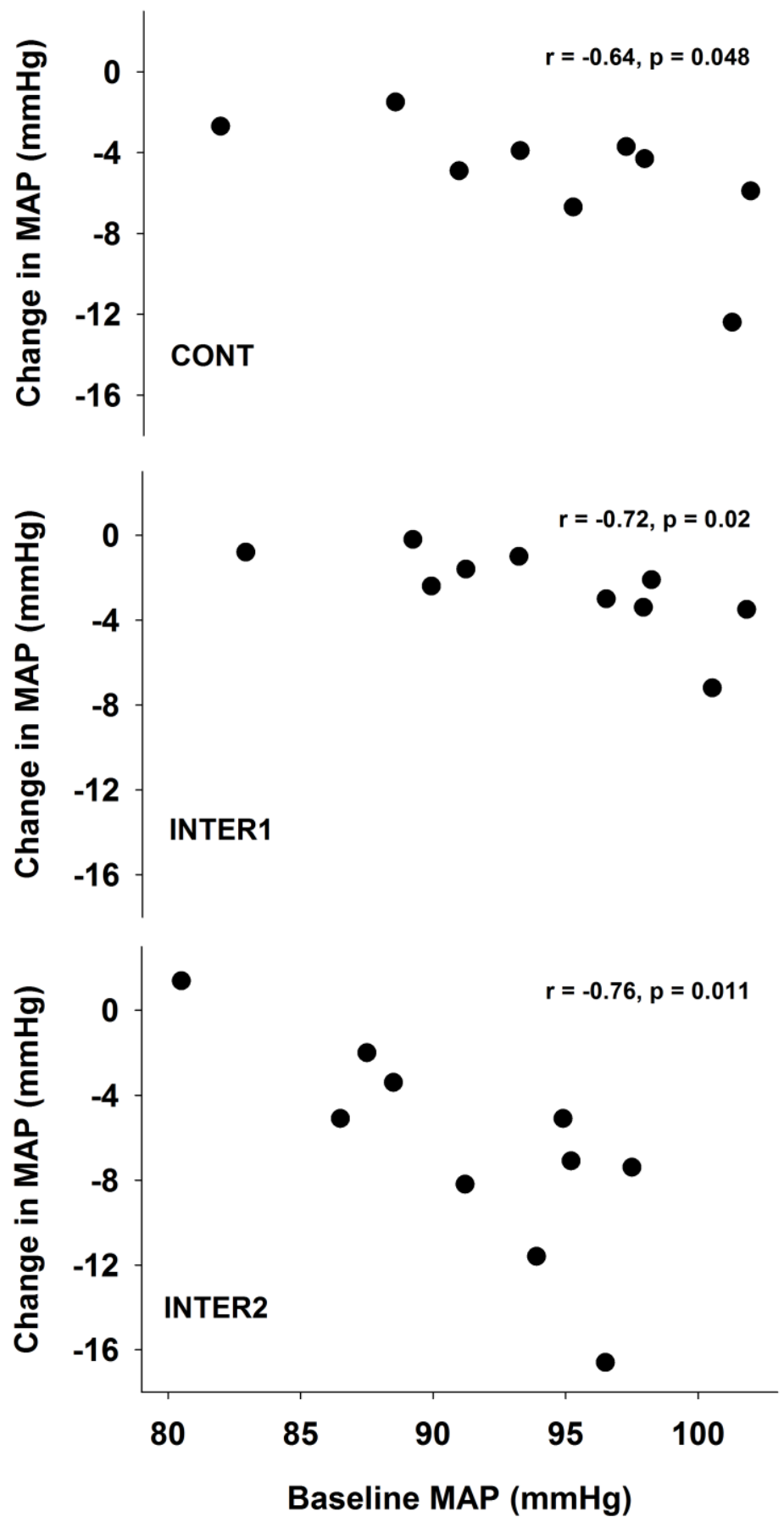

Figure 4. Relationship between baseline mean arterial pressure (MAP) and change in MAP after the continuous exercise bout (CONT), the first intermittent exercise bout (INTER1), and second intermittent exercise bout (INTER2). 

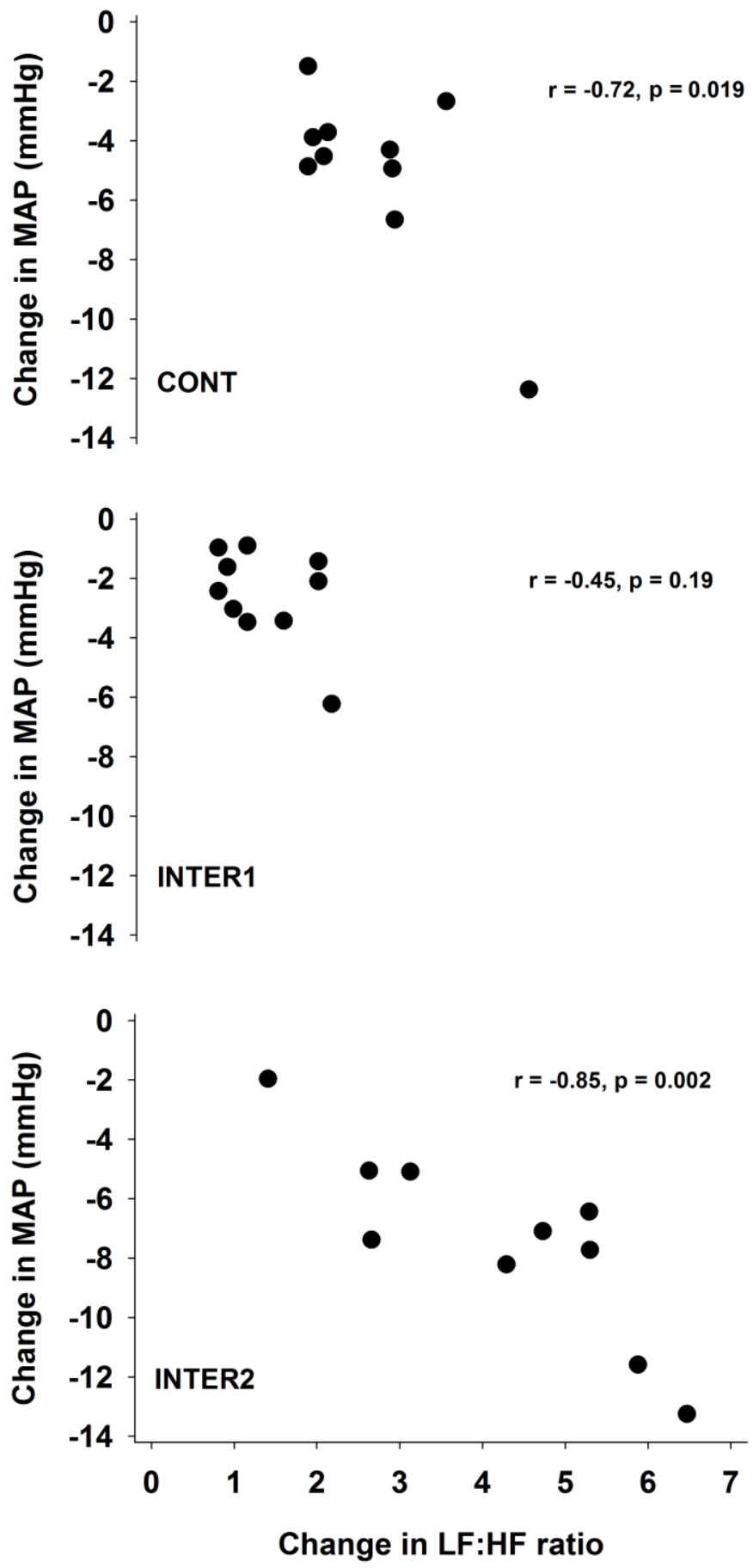

Figure 5. Relationship between the change in the LF:HF ratio and the change in mean arterial pressure (MAP) after the continuous exercise bout (CONT), the first intermittent exercise bout (INTER1), and second intermittent exercise bout (INTER2). 